\title{
LONG-TERM AGROCHEMICAL DYNAMICS: ENGINEERING, APPLICATION AND CHALLENGES OF CALCAREOUS SAPROPEL AS A SOIL FERTILIZER
}

\author{
C.A. BOOTH ${ }^{1}$, E. BAKSIENE ${ }^{2}$, M.A. FULLEN ${ }^{3}$ \& A. CIUNYS ${ }^{4}$ \\ ${ }^{1}$ SEBE, The University of Wolverhampton, UK \\ ${ }^{2}$ Voké Branch of the Lithuanian Institute of Agriculture, Vilnius, Lithuania. \\ ${ }^{3}$ SAS, The University of Wolverhampton, UK. \\ ${ }^{4}$ The Lithuanian Agricultural University, Kaunas, Lithuania.
}

\section{ABSTRACT}

Sapropel (a lake-derived organic-rich mud) has been utilized as a soil fertilizer on sandy and loamy Cambisols in Lithuania. Replicated treatments (including sapropel at $200 \mathrm{t} \mathrm{ha}^{-1}$ ) were applied to crop rotations (maize, barley, clover, winter rye, potatoes and oats) and long-term influences on soil physico-chemical properties and crop yield examined. Soil agrochemical properties were evaluated before (1984-85) and after the end of the first (1989-90), second (1995-96) and third (2001-02) crop rotations from four treatments and four replicates. Results reveal that, in most cases, there are notable increases in soil $\mathrm{pH}$, total absorbed bases, available phosphorus and potassium and soil organic matter content after each crop rotation. Moreover, results show that sapropel can improve crop productivity to comparable levels as manure-fertilized soils. This indicates that there are longterm benefits of sapropel applications, namely improvements in soil properties and associated influences on crop productivity. However, sapropel extraction and application requires sound environmental management of the risks involved so as to provide safe, practical, commercial and sustainable resources for the countries with these deposits. Management should accord with EU directives on soil, water and farming practices.

Keywords: agrochemical properties, carbon sequestration, crop yield, environmental engineering, eutrophication, Lithuania, soil fertility.

\section{INTRODUCTION}

Sapropel is an organic-rich mud extracted from lakes. Once dried and granulated, it can be applied to agricultural lands as a soil fertilizer and conditioner [1]. Furthermore, it is also produced as a nutrient-supplement feed for farm animals and used for cosmetic products and medical applications [2]. In fact, due to its diverse commercial applications, many East European countries consider their sapropel reserves as enormous national natural resources ( 225 billion tonnes in Russia alone) with immense market value.

The value and importance of these freshwater resources necessitates that the lakes are well managed. Sapropel extraction provides socio-economic rewards for small to medium enterprises (SMEs) and benefits the environmental quality of lakes, by reducing eutrophication caused by excessive nutrient in-wash and soil erosion. Furthermore, extraction impedes the silting of lakes and their conversion to marshland.

Besides providing a rich source of organic matter; chemically, sapropel contains most macroand micro-nutrients necessary for plants and they comprise bioactive substances, such as vitamins, enzymes and antibiotics [3]. Furthermore, they accommodate relatively low quantities of cellulose decomposing bacteria, supporting slow mineralization and enabling prolonged fertilizer-life compared with other organic fertilizers [4].

This article aims to: (i) present the results from a long-term agricultural case study in eastern Lithuania, where soil properties and crop production have been monitored, and (ii) highlight the importance of developing sound environmental management strategies for the risks involved with sapropel extraction and application, contained within the framework of EU directives on soil, water and farming practices, so as to provide a safe, practical, commercial and sustainable resource. 


\section{SAPROPEL RESOURCES AND REWARDS}

Lakes are extremely common in areas affected by the Last Glaciation (Weichselian/Devensian); for example, in Lithuania (total area $65,200 \mathrm{~km}^{2}$ ) there are 2,830 lakes each $>1$ ha. Sediment accumulations on their floors are often quite thick, sometimes $>20 \mathrm{~m}$, and are rich (15-90\% by weight) in both autochthonous and allochthonous organic matter. Many also contain calcium carbonate and so have considerable potential as soil liming agents. Once extracted and dried (Fig. 1), spreading of sapropel on sandy soils can improve their physical structure, nutrient status, $\mathrm{pH}$ and resistance to erosion (i.e. decrease soil erodibility) [5]. Removal of mud is also beneficial to lake ecosystems, helping prevent eutrophication by release of nutrients from the sediment.

Lake sapropels are categorized into several types: organic (50-90\% organic matter), calcareous (30-60\% calcium carbonate), siliceous (25-45\% silica) and mixed. Sapropels are commercially

(a)

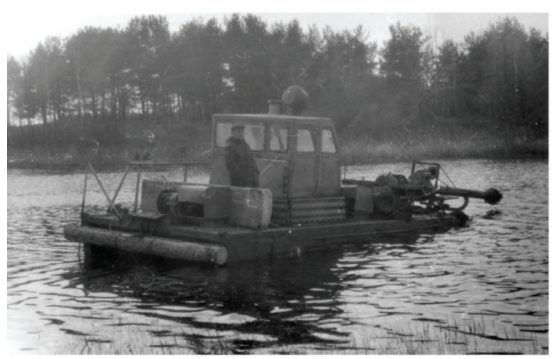

(c)

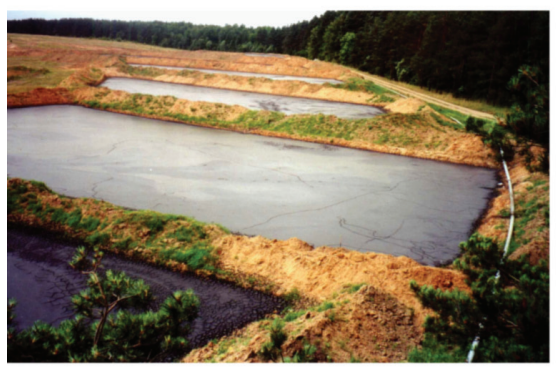

(e)

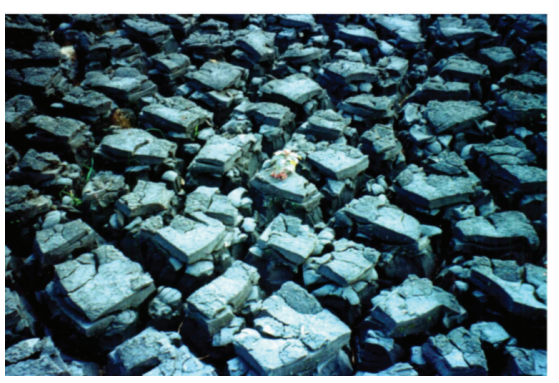

(b)

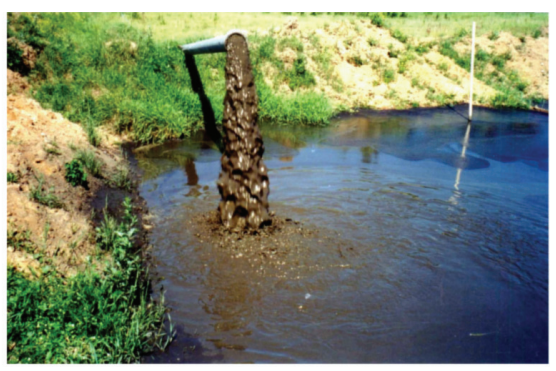

(d)

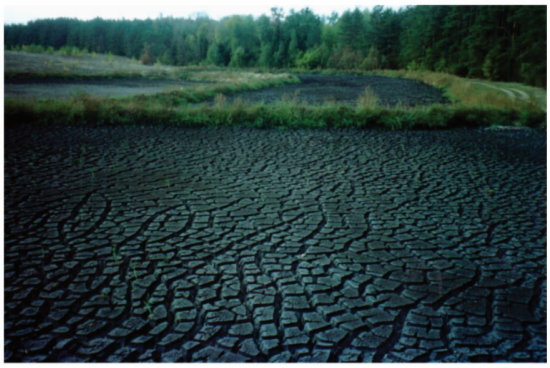

(f)

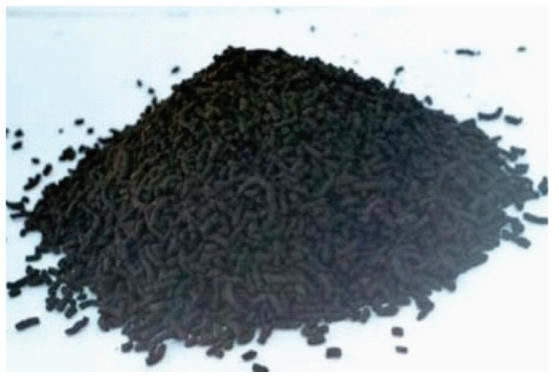

Figure 1: (a and b) Commercial sapropel extraction from Lake Ilgutis $\left(54^{\circ} 34^{\prime} \mathrm{N}, 25^{\circ} 04^{\prime} \mathrm{E}\right)$ and (c-f) sapropel preparation. 
Table 1: Equivalent commercial prices (in 2005) of sapropel in Eastern Europe (100 kg dry weights).

\begin{tabular}{lc}
\hline Country & Sapropel cost $(€)$ \\
\hline Russian Federation & $7-15$ \\
Belarus & 25 \\
Ukraine & 14 \\
Latvia & $12-16$ \\
Lithuania & $18-26$ \\
\hline
\end{tabular}

available in Lithuania, Latvia, Belarus, Russia and the Ukraine (Table 1). Moderate commercial costs of sapropel suggest that the approach is both ecologically and economically sound. Russia holds the largest sapropel resource in the world with an estimated 225 billion tonnes, about $90 \%$ of the total world resource. The Kaliningrad Region alone has an estimated reserve of 15.4 million tonnes $(\mathrm{mt})$ of sapropel, none of which is currently exploited and the estimated total sapropel resources of Karelia Province exceeds 17 billion $\mathrm{m}^{3}$. Lithuania and the Ukraine are estimated to hold reserves of 10.5 and $30 \mathrm{mt}$, respectively. Latvian reserves are $\sim 12 \mathrm{mt}$. Belarus has reserves of all four types of sapropel, which total 1,759 million $\mathrm{m}^{3}$.

\section{EXTRACTION, PROCESSING AND DEVELOPMENT OF SAPROPEL}

Sapropel is extracted by dredging lake bottoms. The sapropel slurry is pumped through pipes to nearby storage pools, where the material is left to dry before being granulated as a fertilizer (Fig. 1a-f). There are several phases of abstraction. The depths of both the lake and water table must be surveyed. Next, it is necessary to construct sapropel sedimentation lagoons, and then assemble dredgers and extraction pipelines. The number and capacity of sedimentation lagoons must correspond to the amount of sapropel dredged from the lakes during each season. Before dredging starts, the lake is partitioned into sectors and routes (a sector is a section of the lake that will be dredged every season, while the route is the strip within a sector to be cleaned by each sweep of the dredge).

Dredging starts along the routes, with the dredger moving from the pelagial zone to the shore. A submersible extraction pump moves from one side of the route to the other and extracts the upper layer of sapropel. After movement from one side of the route to another is completed and the upper layer of sediments is dredged, the pump is submersed into deeper layers of sediment and the process is repeated. When the necessary depth is reached in one route, the dredger goes to the next route and continues the process until the sector or entire lake is dredged.

The extracted pulp consists of sapropel slurry and is transported via pipelines to sedimentation lagoons. Practical experience shows that it is better to discharge sapropel to sedimentation lagoons by layers: after placing $0.2-0.3 \mathrm{~m}$ of sapropel in one sedimentation lagoon, then the same to another, the third and so on, until all the sedimentation lagoons are filled by the first layer of sapropel. Usually it takes 10-20 days to fill all the lagoons with one layer. During this period, sapropel undergoes drying and its volume decreases three- to four-fold. Then the second layer of sapropel is distributed among all the sedimentation lagoons using the same procedures. The first layer of sapropel acquires hydrophobic properties and so does not re-wet. After filling lagoons with 3-4 layers of sapropel, its thickness usually reaches $\sim 0.8 \mathrm{~m}$. Then sedimentation lagoons are left for winter.

Dry sapropel becomes very hard and resistant to mechanical impact. Sapropel clumps are resistant to water and are virtually biologically inactive. That is why freezing of sapropel improves its structure. 
Frost breaks the sapropel clods, so sapropel subject to freeze-thaw processes has markedly different properties from sapropel slurry. It is light and odourless and has lower density, a porous structure and high infiltration and water release capacities.

In recent years, conditioning of sapropel by freezing has become difficult due to mild winters: with only $0.32-0.36 \mathrm{~m}$ depth of sapropel freezing. In order to freeze the entire quantity of sapropel sometimes the frozen surface layer is removed from sedimentation lagoons, exposing deeper layers to frost. In spring, frozen sapropel melts, dries and remains light and crumbly. This sapropel is a versatile product, and can be packed and/or stored for an almost unlimited period and used for many fertilization needs, either alone or mixed with additives.

In the context of the production of sapropel, there is an underdevelopment of the formal institutional environment. This extends from legislation and control in regard to 'new' products and processes, input and output channels, including sourcing of particular inputs and the disposal and marketing of output, networks of producers, networking with public authorities and agencies, including information access. The extent, to which producers of sapropel in Eastern Europe face these obstacles, is unclear, since there is a drastic transformation in the whole institutional environment, in order to conform to market requirements.

Although interest in sapropel products has increased in recent years, an analysis of the sapropel sector, which does not include external benefits and costs associated with the industry, would be limited in its scope. The external costs include the maintenance of ecological functions (i.e. water quality, carbon storage and biodiversity) and aesthetic values in the context of mixed land uses that may be considerable.

Output of sapropel products is a growing market niche, which is at varying stages of development across Eastern Europe. The size of production in any country depends on supply and demand conditions in that country and on international product mobility. Although neo-classical economics attributes production decision-making to objectives like income or profit maximization, which depends on the use of inputs, primarily under the control of the producer, it is clear that individual producer's decisions and, thus, the local market supply is very strongly influenced by the local institutional environment.

\section{AN AGRICULTURAL CASE STUDY FROM EASTERN LITHUANIA}

Lithuania was eroded by fluvioglacial processes during the Quaternary, resulting in a landscape of abundant depressions. Consequently, Lithuania is known as 'the land of lakes'. Despite its small size $\left(65,200 \mathrm{~km}^{2}\right)$, Lithuania has 2,830 lakes $>1$ ha, many of which are silting and transforming into marshy wetlands of decaying vegetation. Hence, the explanation of the word 'sapropel', from the Greek, 'sapro' meaning decay and 'pelos' meaning silt.

Many Lithuanian silt-lakes are located in the south-eastern region of Vilnius, where most soils are typically nutrient-deficient erodible sandy soils. Thus, sapropel is a local and readily available fertilizer source. Conveniently, sapropel can be extracted from near-by lakes for agricultural soil amelioration. All sapropel varieties have been applied to infertile soils and have improved their physico-chemical properties, thus increasing plant productivity [6].

Fertilization with sapropel enriches the soil with organic matter, improves soil structure, physical properties and decreases erodibility. Furthermore, it provides long-term improvements in soil agrochemical and physical properties $[4,6,7]$. The efficacy of sapropel increases notably when composted with manure, resulting in increased microbial populations and nutrients [8].

Experiments to evaluate the long-term fertilization potential of calcareous sapropel have been conducted by the Voke Branch of the Lithuanian Institute of Agriculture since 1984. Sapropel decomposes very slowly in soil; therefore, studies have evaluated the longevity of effects on the soil's agrochemical properties and crop yield [1]. 
4.1 Field treatments and analyses

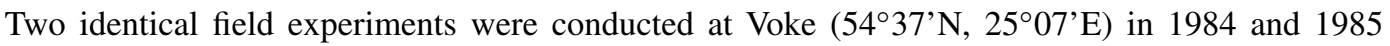
to study the efficacy of calcareous sapropel on sandy loam Haplic Luvisols. Pre-experimental soil agrochemical properties were determined (Table 2). Replicated ( $\mathrm{x} 4)$ experimental plots $\left(40 \mathrm{~m}^{2}\right)$, with a randomized design, were applied with several treatments, of which, four are presented in this

Table 2: Mean agrochemical indices for the various treatments. For comparison and information - preexperimental soil agrochemical properties were: $\mathrm{pH}_{\mathrm{KCl}} 6.1$, mobile $\mathrm{P} 101-115 \mathrm{mg} \mathrm{kg}^{-1}, \mathrm{~K}$ $132-161 \mathrm{mg} \mathrm{kg}^{-1}$ and organic carbon $1.05-1.13 \%$; sapropel contained: $\mathrm{N} 1.20 \%, \mathrm{P} 0.041 \%$, $\mathrm{K} 0.005 \%, \mathrm{Mg} 7.89 \%, \mathrm{CaCO}_{3} 33.0 \%$ and organic carbon $14.8 \%$ by weight dry matter; and manure contained: N 2.10-2.32\%, P $0.26-0.33 \%, \mathrm{~K} 1.08-1.63 \%$ and $\mathrm{Ca} 1.12-1.26 \%$ of dry matter.

\begin{tabular}{|c|c|c|c|c|}
\hline & $1984-85$ & 1989-90 & 1995-96 & $2001-02$ \\
\hline \multicolumn{5}{|l|}{ Soil pH } \\
\hline Treatment A & 6.18 & 6.61 & 6.65 & 6.10 \\
\hline Treatment B & 5.96 & 6.40 & 6.36 & 6.27 \\
\hline Treatment $\mathrm{C}$ & 6.08 & 7.23 & 7.38 & 7.23 \\
\hline Treatment D & 6.15 & 6.48 & 6.35 & 6.52 \\
\hline \multicolumn{5}{|c|}{ Absorbed bases (m equiv kg ${ }^{-1}$ ) } \\
\hline Treatment A & 95.88 & 112.75 & 124.50 & 120.50 \\
\hline Treatment B & 88.88 & 107.13 & 110.88 & 92.00 \\
\hline Treatment $\mathrm{C}$ & 90.50 & 468.25 & 371.13 & 248.33 \\
\hline Treatment D & 91.63 & 132.13 & 126.50 & 97.00 \\
\hline \multicolumn{5}{|c|}{ Humus ( $\%$ by weight) } \\
\hline Treatment A & 1.93 & 1.82 & 2.01 & 1.72 \\
\hline Treatment B & 1.88 & 1.79 & 1.92 & 1.84 \\
\hline Treatment $\mathrm{C}$ & 1.85 & 3.05 & 2.48 & 2.15 \\
\hline Treatment D & 1.86 & 2.55 & 2.30 & 2.01 \\
\hline \multicolumn{5}{|l|}{ Nitrogen $(\%)$} \\
\hline Treatment A & 0.13 & 0.08 & 0.11 & 0.12 \\
\hline Treatment B & 0.13 & 0.08 & 0.12 & 0.25 \\
\hline Treatment C & 0.13 & 0.15 & 0.14 & 0.14 \\
\hline Treatment D & 0.13 & 0.13 & 0.14 & 0.12 \\
\hline \multicolumn{5}{|c|}{ Phosphorus (mg kg-1) } \\
\hline Treatment A & 296.25 & 245.50 & 179.50 & 295.00 \\
\hline Treatment B & 290.63 & 280.00 & 229.25 & 330.17 \\
\hline Treatment $\mathrm{C}$ & 283.75 & 308.25 & 274.75 & 373.83 \\
\hline Treatment D & 301.25 & 286.88 & 232.88 & 357.17 \\
\hline \multicolumn{5}{|c|}{ Potassium $\left(\mathrm{mg} \mathrm{kg}^{-1}\right)$} \\
\hline Treatment A & 193.88 & 121.25 & 118.13 & 140.00 \\
\hline Treatment B & 185.88 & 169.75 & 204.50 & 205.67 \\
\hline Treatment $\mathrm{C}$ & 200.00 & 151.13 & 210.38 & 232.33 \\
\hline Treatment D & 195.25 & 163.63 & 255.25 & 247.00 \\
\hline
\end{tabular}


study: (A) control (without fertilizers); (B) mineral Fertilizers (NPK); (C) NPK $+200 \mathrm{t} \mathrm{ha}^{-1}$ dry sapropel; and (D) NPK $+30 \mathrm{t} \mathrm{ha}^{-1}$ of dry manure.

Treatments were applied to the crop rotation of maize (Zea mays L.), undersown barley (Hordeum L.), clover (Trifolium pratense L.), winter rye (Secale cereale L.), potatoes (Solanum tuberosum L.) and oats (Avena sativa L.). Sapropel was applied in 1984 and 1985 to the first crop (maize) in the rotation and this was the only sapropel applied during the three rotations. Because manure decomposition is much more rapid than sapropel, straw manure was applied in each crop rotation (1984-85, 1990-91, 1995-96). Mineral fertilizers were spread on the soil before sowing each crop of the rotation each year. These were maize: $\mathrm{N}_{120} \mathrm{P}_{26} \mathrm{~K}_{100}$, barley: $\mathrm{N}_{30} \mathrm{P}_{26} \mathrm{~K}_{50}$, clover: $\mathrm{P}_{26} \mathrm{~K}_{50}$, winter rye: $\mathrm{N}_{60} \mathrm{P}_{26} \mathrm{~K}_{50}$, oats: $\mathrm{N}_{60} \mathrm{P}_{26} \mathrm{~K}_{50}$ and potatoes: $\mathrm{N}_{90} \mathrm{P}_{26} \mathrm{~K}_{100}$.

Soil samples were taken $(0-25 \mathrm{~cm}$ depth) from the six treatments and four replications before the experiments (1984-85) and again after completion of the first (1989-90), second (1995-96) and third (2001-02) crop rotations, after harvesting of the last crop (oats) in the rotation [1].

\subsection{Results and discussion}

Experimental results show that over 18 years, most treatments experienced increased soil $\mathrm{pH}$ (Table 2 ). Sapropel treatment is significantly different from treatment B $(P<0.05)$. It is apparent that sapropel treatment caused the greatest increase in absorbed bases, which were markedly higher than each of the other treatments. Sapropel treatment is significantly different from treatment B $(P<0.05)$. Sapropel and manure treatments both demonstrate sizeable increases in humus content, which are notably higher than the other treatments. Nitrogen does not show any obvious trends between the treatments. Sapropel treatment is significantly different from treatment A $(P<0.05)$. Sapropel treatment caused the greatest increases in phosphorus, which are higher than other treatments. However, sapropel treatment was not significantly different from any treatment $(P>0.05)$. Sapropel and manure treatments both demonstrate similar increases in potassium, which are greater than the other treatments (sapropel treatment was significantly different from treatment $\mathrm{A}(P<0.05))$. From these data, it is evident that sapropel treatment does have statistically significant differences with treatments $\mathrm{A}$ and $\mathrm{B}(P<0.05)$. However, for each of the agrochemical parameters, sapropel treatment does not show any statistically significant difference from the manure treatment.

Results of crop yield for each treatment are presented in Table 3. For all crop rotation years, sapropel and manure values are both higher than the other treatments. However, sapropel treatment had the greatest feed unit yield after the first crop rotation and similar feed unit yields to the manure treatment for the second and third crop rotations [1]. At the end of the crop rotation experiment,

Table 3: Total crop yields (expressed as feed units [9]) for each treatment.

\begin{tabular}{lcccr}
\hline & $\begin{array}{c}\text { First crop } \\
\text { rotation total }\end{array}$ & $\begin{array}{c}\text { Second crop } \\
\text { rotation total }\end{array}$ & $\begin{array}{c}\text { Third crop } \\
\text { rotation total }\end{array}$ & Total \\
\hline Treatment A & 21875 & 18169 & 14540 & 54584 \\
Treatment B & 30199 & 21521 & 19487 & 71207 \\
Treatment C & 32113 & 23018 & 21943 & 77074 \\
Treatment D & 30855 & 24740 & 22271 & 77866 \\
Total & 115042 & 87448 & 78241 & 280731 \\
\hline
\end{tabular}


sapropel and manure treatments yielded similar total feed units. Although a breakdown of the feed unit data is not shown, during years when potatoes and oats were cultivated in rotation, sapropel rates decreased productivity.

In the second crop rotation, productivity increased from the repeated introduction of manure and further effects of the sapropel were even more efficient. Data shows a cumulative increase from the beginning of the third crop rotation (1997), but in 2001 and 2002 when potatoes and oats were cultivated, productivity, as in previous rotations, decreased. A plausible explanation is that since potatoes and oats are more tolerant of acid soils, the large amounts of $\mathrm{Ca}^{2+}$ ions introduced into the soil with calcareous sapropel decreased the availability of $\mathrm{K}$ and other nutrients that affect potato and oats yields.

The trends in these crop data are similar to previous studies, where both organic and siliceous sapropels increased agricultural crop yields [4]. Based on these studies, it can be argued that fertilization with sapropel enriches soil with organic matter, improves soil structure, physical properties and decreases erodibility. Furthermore, it provides long-term improvements in soil agrochemical properties $[4,6,7]$. The efficacy of sapropel increases notably when composted with manure, resulting in increased microbial populations and nutrients [8].

\section{POTENTIAL CHALLENGES AND THE NEED FOR FURTHER STUDY}

Sapropel extraction provides socio-economic rewards for SMEs and benefits the environmental quality of lakes, by reducing the eutrophication caused by excessive nutrient in-wash, soil erosion and sewage input. However, it is the direct and indirect transport and deposition of agricultural and industrial waste materials into lakes, which identifies them as the ultimate depository environment or natural 'sink' for fluxes of many chemical and biological pollutants from both natural and anthropogenic sources. Environmental contamination may be related to point sources (industrial discharges and waste plant effluents) or more frequently, to diffuse sources (atmospheric transport and deposition, plus excessive nutrient loading from agricultural catchments). Lake toxicity is dependent on the concentration and type of pollutant, proximity to pollution sources and the environmental conditions of the lake. For instance, these problems have occurred in Lakes Kuetsjarvi and Ladoga (northwest Russia), despite past decades of international environmental improvements and national government pollution control orders in decreasing contemporary pollution. Given the decades of organic input and anaerobic biochemical decomposition necessary to produce significant thicknesses of sapropel, it is the disturbance, resuspension, mobility and bioavailability of historical contaminants that pose an environmental threat to lake water quality and its ecological balance. Likewise, once extracted, sapropel application poses a detrimental environmental risk, because previously lake-locked pollutants can be transferred to the soil, water and then to the food chain. The value and importance of freshwater resources necessitates that lakes are well managed, especially where human actions influence domestic, agricultural and industrial pollution.

In recent years, sapropel has been increasingly used as fertilizers and fodder additives in Eastern Europe. However, thorough geochemical and biological investigations are required to elucidate the essential differences in the composition of different regional sapropels, exposed to various agricultural and industrial waste contaminants. Likewise, a wide range of element concentrations permits the selection of lakes and deposits with the most valuable properties for these uses. The agrochemical effectiveness of sapropel is determined by the content of nitrogen, phosphorus, potassium, trace elements, texture, the humic and fulvic acids content, the amount of biologically active substances and the level of exchangeable acidity. Industrial effluents, agricultural runoff, vehicle transport, burning of fossil fuels, animal and human excretions and geological weathering, and domestic waste contribute heavy metals (such as organo-lead, organo-mercury and cadmium) to 
water bodies. So it is also important to evaluate the content of harmful components. Particular concern surrounds the highly toxic contaminants, such as pesticides, benzapyrine, polycyclic aromatic hydrocarbons (PAHs), polychlorinated dibenzo- $p$-dioxins and furans (PCDD/Fs), coplanar polychlorinated biphenyls (PCBs), dichlorodiphenyl-trichloroethane isomers (DDTs) and pathogenic micro-organisms. Pollutant accumulations in aquatic food chains are undesirable, because of their chronic adverse effects on aquatic organisms, wildlife and humans. Thus, risk assessment of these adverse effects relies on accurate modelling of water, sediment and biota data.

To date, sapropel continues to be extracted from European lakes and is made commercially available to agricultural and livestock farmers, albeit mostly in Eastern Europe. However, its extraction and application requires sound environmental management of the risks involved, so as to provide a safe, practical, commercial and sustainable resource. To achieve this, the formulation of a rigorous protocol conforming to EU regulations contained within the framework of EU directives on soil, water and farming practices and the 'Essential Requirements for CE' (Conformitée Européenne) marking and certification is required. Without this protocol, land-managers will continue to be unable to assess risks with sapropel application. Therefore, the following topics require further investigation:

1. Historical development and current status of sapropel deposits, including current practice, legislation and the style and management of extraction.

2. Effects of sapropel extraction on water quality and its implications for environmental resource management and advanced technologies.

3. Effects of sapropel application on soil conservation, carbon sequestration, nutrient management, biodiversity, soil water quality and its potential impact on the food chain.

4. Effects of sapropel application on the functioning and integrity of soil biological systems.

5. Effects of sapropel application for animal feed and its influence on animal health and nutrition.

6. Socio-economic impact, development and sustainability of sapropel resources, from both legal and commercial perspectives.

\section{CONCLUSIONS}

Use of calcareous sapropel for fertilization on sandy loam Haplic Luvisols usually had positive and some negative effects. Effects include decreased soil acidity, increased amounts of absorbed bases, humus, total $\mathrm{N}$ and available $\mathrm{P}$, while available $\mathrm{K}$ decreased. By the end of the second and third crop rotations, the influence of sapropel on soil agrochemical properties remained generally positive. Long-term, sapropel increased crop productivity, with almost the same effectiveness as manure. However, sapropel decreased potato and oat yields.

Despite the socio-economic rewards for SMEs, its benefits for the environmental quality of lakes and the positive attributes of sapropel fertilizers for improving soil properties and crop yields, sapropel extraction and application requires sound environmental management of the risks involved, so as to provide safe, practical, commercial and sustainable resource.

Future research needs to: (i) ensure sapropel resources (where possibly contaminated with agricultural and industrial pollutants) pose minimal risk to soil, water and the food chain; (ii) safeguard the resource from overexploitation; and (iii) promote SME development and efficiency.

\section{ACKNOWLEDGEMENTS}

The authors gratefully acknowledge the help and assistance provided by the staff at the Voke Branch of the Lithuanian Institute of Agriculture, Vilnius, Lithuania. 


\section{REFERENCES}

[1] Bakšienė, E., Fullen, M.A. \& Booth, C.A., Agricultural soil properties and crop production on Lithuanian sandy and loamy Cambisols after the application of calcareous sapropel fertilizer. Archives in Agronomy and Soil Science, 52, pp. 201-206, 2006.

[2] Eco-Sapropel, Cosmetic products based on pelosilts. http://www.eco-sapropel.ru/.

[3] Kershaw, A.P., A modification of the Troels-Smith system on sediment description and portrayal. Quaternary Australasia, 15, pp. 63-68, 1997.

[4] Orlov, D.S. \& Sadovnikova, L.K., Nontraditional ameliorants and organic fertilizers. Eurasian Soil Science, 29, pp. 474-479, 1996.

[5] Baksiene, E., Changes in the properties of light textured soils in relation to lake sediment fertilization. Proceedings of the 12th International Soil Conservation Organization Conference, May 26-31, Beijing, China, pp. 291-295, 2002.

[6] Tsekhanovich, YuU, Susha, A.U. \& Svarba, V.F., Effects of different sapropels on crop yield as a function of their doses and moisture. Vyestsi Akademii Ahrarnykh Navuk Byelarusi Minsk, pp. 11-14, 1993.

[7] Kronbergs, A. \& Viduzs, A., The value of organic fertilizers and sapropel. Raziba, 8, pp. 24-27, 1993.

[8] Salina, O., Repečkiene, J., Lugauskas, A. \& Baksiene, E., Variation of micro-organisms in Haplialbic Arenosols fertilized with sapropel of various chemical composition. Agriculture - Scientific Article, 76, pp. 87-102, 2001.

[9] Moore, J.E. \& Undersander, D.J., Relative forage quality: an alternative to relative feed value and quality index. Proceedings of the 13th Annual Florida Ruminant Nutrition Symposium, pp. 16-32, 2002. 